\title{
A Prospective, Multicenter Study on Efficacy of Long-Acting Testosterone Undecanoate, If Desired in Combination with Vardenafil, in Late Onset Hypogonadal Patients with Erectile Dysfunction
}

\author{
Sompol Permpongkosol ${ }^{1^{*}}$, Krisada Ratana-Olarn ${ }^{1}$, Anupan Tantiwong ${ }^{2}$, Kavirach Tantiwongse ${ }^{3}$, \\ Apichat Kongkanand ${ }^{4}$ \\ ${ }^{1}$ Department of Surgery, Faculty of Medicine, Ramathibodi Hospital, Mahidol University, Bangkok, Thailand \\ ${ }^{2}$ Department of Surgery, Faculty of Medicine, Siriraj Hospital, Mahidol University, Bangkok, Thailand \\ ${ }^{3}$ Department of Surgery, Chulalongkorn University, King Chulalongkorn Memorial Hospital, Bangkok, Thailand \\ ${ }^{4}$ Department of Urology, Bumrungrad International Hospital, Bangkok, Thailand \\ Email: * sompolpermpong@gmail.com
}

Received May 2, 2013; revised June 3, 2013; accepted June 10, 2013

Copyright (C) 2013 Sompol Permpongkosol et al. This is an open access article distributed under the Creative Commons Attribution License, which permits unrestricted use, distribution, and reproduction in any medium, provided the original work is properly cited.

\begin{abstract}
Introduction: There is substantial evidence suggesting the additive effect on erectile function (ED) of testosterone and phosphodiesterase (PDE)-5 inhibitors. But the combination of long-acting testosterone undecanoate (TU), in combination with the PDE5-I vardenafil men with with late-onset hypogonadal patients (LOH) with (ED) has not yet been studied. Aims: To evaluate the effects of TU i.m., and if desired, the PDE5i vardenafil (PDE-5I) in LOH patients with ED measured with the International Index of Erectile Function (IIEF-5). Methods: A prospective study was performed following four administrations of TU in week $0,6,18,30$. If no improvement of ED assessed with IIEF-5 or the Global Assessment Questionnaire (GAQ) in week 12, the PDE5 inhibitor vardenafil was added. The final evaluation was in week 46. Main Outcome Measures: Aging Male Symptom (AMS) score, IIEF-5 score, and International Prostate Symptoms Score (IPSS) at each visit were summarized as mean with standard deviation; while GAQ was summarized using frequency and percentage. Scores at each visit were also categorized into different levels of symptom severity. Results: AMS score decreased significantly at week 12, 30 and 46. IIEF-5 score increased but a significant change was found only at week 30 and 46 . The GAQ assessment indicated erection and sexual intercourse already improved at the first assessment continuing thereafter. IPSS score decreased from baseline at week 46. Levels of total, free and bioavailable testosterone had increased significantly from baseline at all visits. Hematocrit, hemoglobin and prostate specific antigen increased significantly from baseline. Adverse events were rare with pain at injection site found in one patient. The two events were non-serious in type, mild in their intensity and recovered. Conclusions: Therapy with TU and, and if desired, combined with the PDE5 inhibitor vardenafil improved sexual activity in LOH patients with ED.
\end{abstract}

Keywords: Testosterone; Hypogonadanism; Erectile Dysfunction; Phosphodiesterase (PDE)-5 Inhibitors

\section{Introduction}

Conservative estimates suggest that approximately $12 \%$ of patients with ED may have subnormal levels of testosterone [1,2]. Hypogonadism on the basis of testicular disease (primary hypogonadism) or hypothalamo-pituitaty disease (secondary hypogonadism is rather easily diagnosed and patients usually receive testosterone replacement. However, decreased testosterone production also

${ }^{*}$ Corresponding author. may occur with advancing age, the so-called late-onset hypogonadism $(\mathrm{LOH})$ or androgen decline in the aging male [2-4]. Recent studies indicate that it is not age per se that determines the severity of $\mathrm{LOH}$, but rather pathologies frequently occurring with advancing age such as obesity, the metabolic syndrome and other chronic medical disorders, such as diabetes type II [5]. It has been and is still debated whether this decline of testosterone is clinically relevant. The international consultation on sexual and erectile dysfunction recommended that adult on- 
set hypogonadism be defined as clinical and biochemical syndrome [6,7] having both clinical signs of androgen deficiency and an objectively low serum testosterone. Testosterone plays a key role in the central and peripheral modulation of erectile function. New research in laboratory animals and in humans is shaping a better definition of the role of testosterone therapy in ED. It appears that testosterone (T) has effects not only on sexual desire, but also on the anatomical and physiological substrate of erection. Hypogonadism, when present, should be treated regardless of age because of the effects of testosterone on bone, muscle and metabolism. At least 30\% - 35\% of men with ED fail to respond to treatment with PDE-5 inhibitors. Several studies indicate synergistic effects of testosterone replacement therapy with a PDE-5 inhibitor [8]. Recently, Kim et al. suggested that combination therapy of TU and tadalafil in PDE5I non-responders with severe and intermediate testosterone deficiency was more beneficial to patients with severe testosterone depletion, possibly by improving underlying pathophysiology of the erectile mechanism [9]. Up to now, long-acting testosterone undecanoate (TU), in combination with vardenafil in men with LOH with ED has not yet been studied. Therefore, in this study the role of TU in the treatment of ED, was monitored and if desired vardenafil was added to evaluate how they benefit LOH patients with ED.

\section{Aims}

Primary objectives are to evaluate the response of a treatment with TU i.m. and, if desired by the patient combined with vardenafil in $\mathrm{LOH}$ patients with ED, using the International Index of Erectile Function (IIEF)-5 score. Secondary objectives were to determine the level of total and free testosterone in the patients under treatment and their impact on the Aging Male Symptom (AMS) and General Assessment Question (GAQ). Furthermore, potentially adverse events, such as changes of hemoglobin and biochemical blood parameters (lipid and glucose profile), prostate specific antigen (PSA) and of digital rectal examination were recorded.

\section{Methods}

The selection criteria for inclusion in the study were patients with ED with a duration over 3 months, age $>18$ years, a stable sexual relationship, low or low normal serum testosterone level TT $<300 \mathrm{ng} / \mathrm{dl}$, $(<10.4 \mathrm{nmol} / \mathrm{L})$ AMS scale with total score starting at 37 points. Subjects who previously took the oral androgen or a PDE-5 inhibitor should have discontinued their use for at least one month. The exclusion criteria were the well-known contra-indications to either testosterone or PDE-5 inhibitors, such as diagnosed or suspected carcinoma of the prostate or the male breast cancer, past or present liver tumors or acute or chronic hepatic diseases.

A total 30 patients with $\mathrm{LOH}$ with ED were entered into the study. The study was composed of 3 phases: screening phase, baseline, and 30-week treatment phase, and follow up. Upon entry of the subject in treatment phase of the study, each subject received TU i.m. (NEBIDO $\left.^{\circledR}\right) 1000$, on week $0,6,18,30$. If the patient did not report improvement of ED as assessed by the IIEF-5 or GAQ in week 12, treatment with vardenafil was added. Doses of vardenafil varied from 5 to $20 \mathrm{mg}$, from week 12 of the study onwards following the advice of the attending physician. The final evaluation was in week 46 . The study did not require any changes in the existing concomitant treatment of the patient. The present protocol did not allow of dose of testosterone. There was no replacement of subjects who drop-out of the study.

\section{Main Outcome Measures}

Demographic and clinical characteristics of patients at baseline were summarized using descriptive statistics including frequency, percentage and mean with standard deviation. Main outcomes including AMS score, IIEF-5 score, and IPSS at each planned visit were summarized as mean with standard deviation; while GAQ was summarized using frequency and percentage. Each of AMS, IIEF-5 and IPSS scores at each visit was also categorized into different level of symptom severity based on well known defined criteria and presented as frequency and percentage. For continuous outcomes, difference between baseline value and each visit for each of outcomes was tested for statistical significance using paired t-test or Wilcoxon signed rank test as appropriate. For categorical outcomes, McNemar test or marginal homogeneity test was used as appropriate. Significance level (Type I error rate) was not adjusted for multiple comparisons.

\section{Results}

Thirty male patients were enrolled, but five patients dropped out and did not visit the center in violation of the protocol requirement. Therefore, data of 25 patients who received a complete set of 4 doses of TU injections were used for analysis. Table 1 demonstrates baseline patient demographics and clinical characteristics. We found that as many as 23 of 25 patients $(92 \%)$ used vardenafil at least once during study periods after the second injection (week 12) when they had had 6 weeks treatment with TU.

Table 2 shows the effect of $1000 \mathrm{mg}$ TU injection on the AMS and IIEF-5. Compared with baseline (44.40), the AMS score decreased significantly at week 12, 30 and 46 (p-value $=0.001,<0.001$ and $<0.001$, respectively). Fifty-two percentages of patients were in moderate level at baseline, while more patients significantly 
Table 1. Baseline patient demographics and clinical characteristics $(\mathrm{N}=\mathbf{2 5}$ male patients).

\begin{tabular}{lc}
\hline Characteristics & $\mathrm{N}(\%)$ \\
\hline Age $(\mathrm{yr})$, mean $\pm \mathrm{SD}$ & $60.81 \pm 10.53$ \\
Weight $(\mathrm{kg})$, mean $\pm \mathrm{SD}$ & $73.62 \pm 11.37$ \\
$\mathrm{BMI}\left(\mathrm{kg} / \mathrm{m}^{2}\right)$, mean $\pm \mathrm{SD}$ & $25.88 \pm 3.26$ \\
Normal weight $\left(18.5-24.9 \mathrm{~kg} / \mathrm{m}^{2}\right)$ & $11(44.0 \%)$ \\
Overweight $\left(25.0-29.9 \mathrm{~kg} / \mathrm{m}^{2}\right)$ & $12(48.0 \%)$ \\
Obesity $\left(\geq 30.0 \mathrm{~kg} / \mathrm{m}^{2}\right)$ & $2(8.0 \%)$ \\
Previously use of hormone replacement & $14(56.0 \%)$ \\
therapy & \\
Medical history & $12(48.0 \%)$ \\
Hypertension & $6(24.0 \%)$ \\
Diabetes & $15(60.0 \%)$ \\
Dyslipidemia & $3(12.0 \%)$ \\
Benign prostatic hyperplasia & $4(16.0 \%)$ \\
Osteoporosis & \\
\hline
\end{tabular}

had less severe symptom at later visits ( $p$-value $=0.002$, $<0.001$ and $<0.001$ at week 12,30 and 46 respectively).

The IIEF-5 score increased (moving to milder symptom) at week 12, 30 and 46, though a significant change was found only at week 30 and 46 (p-value $=0.033$ and 0.003 , respectively). The mean score of 11.56 at baseline suggested a mild to moderate symptom severity. Of the patients $48 \%$ had mild to moderate symptom, $42.1 \%$ patients had mild symptoms at week 46 and $15.8 \%$ had severe symptom $(\mathrm{p}$-value $=0.016)$.

Table 3 demonstrates the effect of $1000 \mathrm{mg}$ TU injection on GAQ and IPSS. Based on GAQ assessment, improved erection was reported in a very high proportion of patients at the first assessment $(100 \%$, at week 12) and later on ( $88 \%$ at week 30 and $95 \%$ at week 46$)$. Improved sexual intercourse was reported to be almost identical to the improved erection at all assessment visits. Regarding prostate symptoms, IPSS score decreased (improved) from baseline at week 46 (from 8.52 to 7.63 ) but statistical significance ( $\mathrm{p}$-value $=0.059$ ) was not reached. Of the patients $48 \%$ were in mild and $48 \%$ were in moderate, severity levels with only $4.0 \%$ with severe level at baseline. No patient had severe levels and more patients (52.6\%) had mild level at visit 8 , such change reached no statistical significance $(\mathrm{p}$-value $=0.375)$.

Table 4 presents laboratory variables. Levels of serum total testosterone, free testosterone and bio-testosterone increased significantly from baseline at all visits. No statistical significant changes were found for SHBG, total cholesterol, HDL, LDL triglyceride, and HbA1C. The hematocrit increased significantly from baseline at week 12,30 and 46 (p-value $<0.001,<0.001$ and 0.001 respectively). Similar to hematocrit, hemoglobin levels also increased significantly from baseline ( $\mathrm{p}$-value $=0.012$, $<0.001$ and 0.001 respectively). Prostate specific antigen
Table 2. Effect of $1000 \mathrm{mg}$ testosterone undecanoate injection on the AMS and IIEF-5 ( $N=25$ patients).

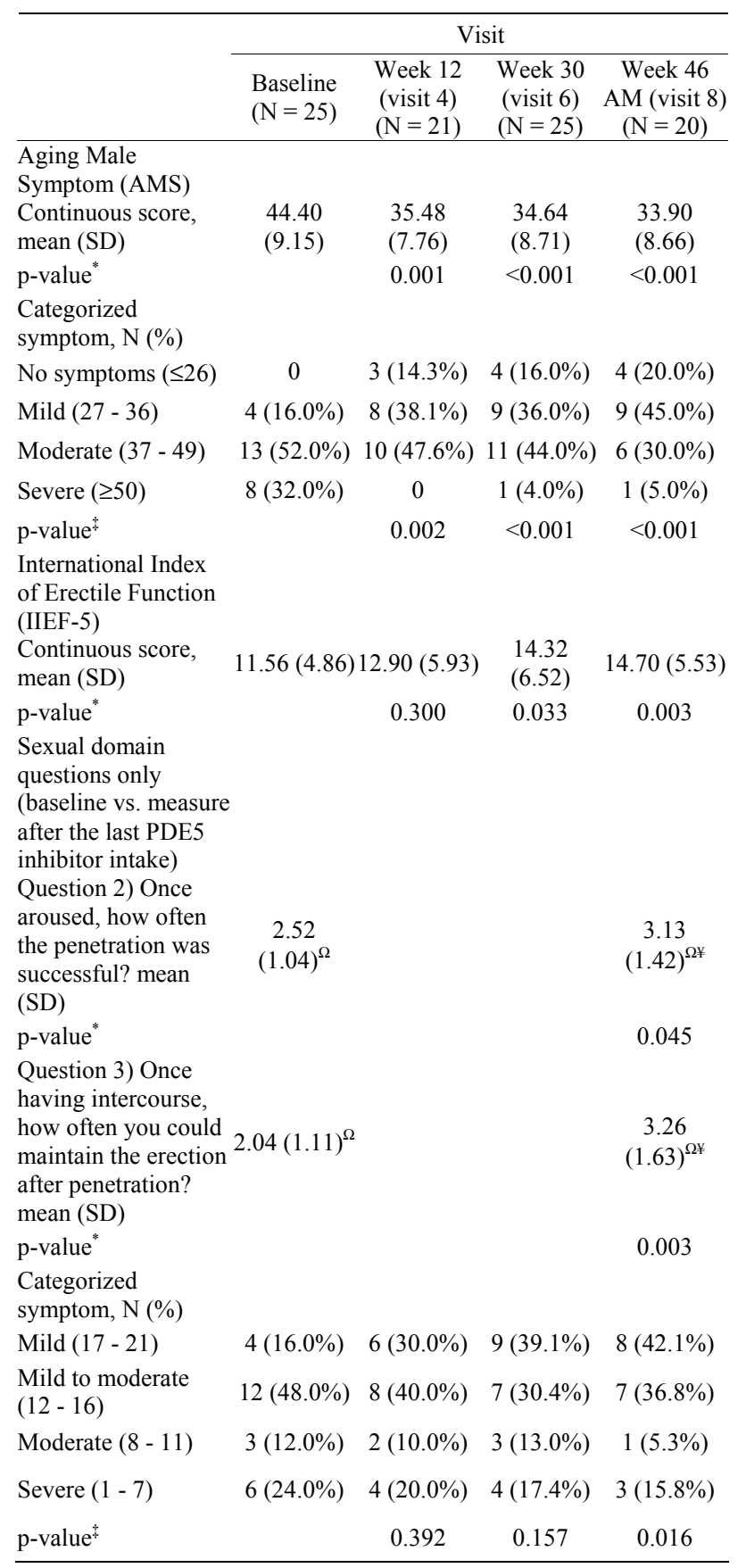

${ }^{*}$ Paired samples t-test, compared with baseline; ${ }^{\dagger} \mathrm{McNemar}$ test, compared with visit $4 ;{ }^{\$} \mathrm{n}=18,{ }^{\#} \mathrm{n}=19,{ }^{\Omega} \mathrm{n}=23 ;{ }^{*}$ The measures of IIEF questions were after the last intake of PDE-5 inhibitor, not the visit 8 ; ${ }^{*}$ Marginal homogenity test, compared with baseline.

was also increased significantly from baseline at visits 4 , 6 and 8 (p-value $=0.002,0.008$ and 0.004 respectively).

With regard to safety, based on all 30 patients enrolled, adverse events with a definite relation with study drug was rare with only pain at injection site found in one patient. The two events were non-serious in type, mild in 
Table 3. Effect of $1000 \mathrm{mg}$ testosterone undecanoate injection on GAQ and IPSS ( $N=25$ patients).

\begin{tabular}{|c|c|c|c|c|}
\hline & \multicolumn{4}{|c|}{ Visit } \\
\hline & $\begin{array}{l}\text { Baseline } \\
(\mathrm{N}=25)\end{array}$ & $\begin{array}{l}\text { Week } 12 \\
\text { (visit 4) } \\
(\mathrm{N}=21)\end{array}$ & $\begin{array}{l}\text { Week } 30 \\
\text { (visit 6) } \\
(\mathrm{N}=25)\end{array}$ & $\begin{array}{c}\text { Week } 46 \\
\text { AM (visit } 8) \\
(\mathrm{N}=20)\end{array}$ \\
\hline \multicolumn{5}{|l|}{ GAQ, n (\%) } \\
\hline Improved erection & & $18(100.0 \%)^{\$}$ & $22(88.0 \%)$ & $19(95.0 \%)$ \\
\hline p-value ${ }^{\dagger}$ & & & 1.000 & 1.000 \\
\hline $\begin{array}{l}\text { Improved } \\
\text { intercourse }\end{array}$ & & $18(100.0 \%)^{\$}$ & $21(84.0 \%)$ & $19(95.0 \%)$ \\
\hline p-value ${ }^{\dagger}$ & & & 1.000 & 1.000 \\
\hline \multicolumn{5}{|l|}{$\begin{array}{l}\text { International } \\
\text { Prostate } \\
\text { Symptoms Score } \\
\text { (IPSS) }\end{array}$} \\
\hline $\begin{array}{l}\text { Continuous score, } \\
\text { mean (SD) }\end{array}$ & $8.52(5.51)$ & & & $7.63(5.33)^{\#}$ \\
\hline p-value ${ }^{*}$ & & & & 0.059 \\
\hline \multicolumn{5}{|l|}{$\begin{array}{l}\text { Categorized } \\
\text { symptom, N (\%) }\end{array}$} \\
\hline Mild (0 - 7) & $12(48.0 \%)$ & & & $10(52.6 \%)$ \\
\hline Moderate (8 - 19) & $12(48.0 \%)$ & & & $9(47.4 \%)$ \\
\hline Severe $(20-35)$ & $1(4.0 \%)$ & & & 0 \\
\hline p-value $e^{\frac{1}{x}}$ & & & & 0.375 \\
\hline
\end{tabular}

*Paired samples t-test, compared with baseline; ${ }^{\dagger} \mathrm{McNemar}$ test, compared with visit $4 ;{ }^{\$} \mathrm{n}=18,{ }^{\#} \mathrm{n}=19,{ }^{\Omega} \mathrm{n}=23$; ${ }^{\dagger}$ Marginal homogeneity test, compared with baseline.

their intensity and recovered. Other unrelated adverse events included frequent urination, increased CEA level, statis dermatitis, urinary tract infection, prurigo simplex and dysuria found in one patient each (Table 5).

\section{Discussion}

LOH is increasingly recognized as a clinically significant entity. Many elderly men have complaints of ED. Early studies suggested that the effects of testosterone on male sexuality were primarily related to libido There is accumulating evidence that the integrity of penile erectile mechanisms are dependent on adequate serum testosterone levels. While the advent of the PDE5-I was a breaktrough in the treatment of ED, it appeared in the longer term that their efficacy was not optimal in $30 \%-50 \%$ of men. The combination of restoring testosterone levels to normal, with their presumed effects of improving the anatomical and biochemical substrate of erectile function, with PDE5-I, produced much better results and is now a standard recommendation if one of the treatment modalities (testosterone or PDE5-I) is unsuccessful.

In the present study we tested the efficacy of longacting TU on ED and, if patients desired, the PDE-5 inhibitor vardenafil could be added. The motivation for this study was that this combination had not been studied. Our results indicate that treatment of men with $\mathrm{LOH}$ com- plaining of erectile function are well served with treatment with TU i.m., if necessary sypplemented with vardenafil. There were significant improvements of ED as assessed with the IIEF-5 and GAQ. Also the AMS showed significant improvements.

There were no significant side-effects: the hematocrit and hemagolobin levels increased ans well as serum PSA which is expected when serum testosterone levels in men with hypogonadism are restored to normal. There were no adverse effects on the scores of the IPSS, which rather tended to improve, but results did not reach significance. In one case there was pain at the injection site which dissolved after a couple of days.

The results of this first study finding an efficacious effects of TU with vardenafil added on, with a favorable safety profile encourages us to study the merits of this combination in greater detail in randomized studies.

Hypogonadism is a pathophysiologic and clinical factor in a substantial number of patients with ED, and data indicate that a threshold level of testosterone is necessary for normal erectile function. Testosterone therapy is clearly indicated in hypogonadal patients and is beneficial in other patients with ED and hypogonadism. However, testosterone efficacy as monotherapy for ED could be limited, and combination therapy with testosterone and other ED treatments, such as PDE-5 inhibitors, may be valuable in certain subpopulations of patients. Consequently, testosterone therapy has evolved from a monotherapy for ED in cases of low testosterone, to a combination therapy with PDE-5 inhibitors. There is increasing evidence that combination therapy is effective in treating the symptoms of ED in patients where treatment failed with testosterone or PDE-5 inhibitors alone. Combination therapy may be particularly useful in men with type 2 diabetes, who frequently have hypogonadism. Additional studies are required to assess full utilization of combination therapy.

In combination therapy including testosterone and PDE-5 inhibitors, PDE-5 inhibitors work in synergy with the body to promote erectile function by inhibiting PDE5, which breaks down cGMP $[10,11]$. Clinical evidence in men with ED indicates that oral PDE5 inhibitorssildenafil, tadalafil, and vardenafil — have favorable safety and efficacy profiles in the treatment of ED [8]. Consequently, PDE-5 inhibitors are the first line of therapy in men who do not have potentially reversible causes of ED, such as hypogonadism [12]. Nonetheless, $23 \%$ to $50 \%$ of patients do not respond to PDE-5 inhibitors alone [13]. Given the role of testosterone in the NO pathway central to proper erectile function, interest in PDE-5 testosterone combination therapy has increased in recent years [14].

Testosterone therapy has been found to improve erectile function and the response to PDE-5 inhibitors in patients with ED and hypogonadism [14]. In a randomized, 
Table 4. Laboratory variables $(\mathrm{N}=25$ male patients).

\begin{tabular}{|c|c|c|c|c|c|c|c|}
\hline & \multicolumn{7}{|c|}{ Mean (SD) of laboratory tests by visit $(\mathrm{N}=25)$} \\
\hline & Baseline (Visit 1) & Visit 3 & Visit 4 (wk 12) & Visit 5 & Visit 6 (wk 30) & Visit 7 & Visit 8 (wk 46) \\
\hline \multicolumn{8}{|c|}{ Testosterone (ng/dL) } \\
\hline Total & $239.75(108.94)$ & $\begin{array}{c}458.23(150.84) \\
\quad(\mathrm{N}=24)\end{array}$ & $\begin{array}{c}581.95(143.33) \\
\quad(\mathrm{N}=19)\end{array}$ & $\begin{array}{c}522.99(264.02) \\
(\mathrm{N}=23)\end{array}$ & & $\begin{array}{c}693.42(252.22) \\
\quad(\mathrm{N}=23)\end{array}$ & $\begin{array}{c}479.22(160.59) \\
(\mathrm{N}=19)\end{array}$ \\
\hline p-value & & $<0.001^{*}$ & $<0.001^{\dagger}$ & $<0.001^{*}$ & & $<0.001^{\dagger}$ & $<0.001^{*}$ \\
\hline Free & $5.31(2.76)$ & $\begin{array}{c}10.26(3.96) \\
(\mathrm{N}=24)\end{array}$ & $\begin{array}{l}14.11(3.52) \\
(\mathrm{N}=19)\end{array}$ & $\begin{array}{c}11.95(6.48) \\
(\mathrm{N}=23)\end{array}$ & & $\begin{array}{c}17.86(7.48) \\
(\mathrm{N}=23)\end{array}$ & $\begin{array}{c}11.24(3.81) \\
(\mathrm{N}=19)\end{array}$ \\
\hline p-value & & $<0.001^{\dagger}$ & $<0.001^{\dagger}$ & $<0.001^{*}$ & & $<0.001^{\dagger}$ & $<0.001^{\dagger}$ \\
\hline Bio-testosterone & $\begin{array}{c}126.66(63.51) \\
(\mathrm{N}=20)\end{array}$ & $\begin{array}{l}212.89(67.35) \\
\quad(\mathrm{N}=19)\end{array}$ & $\begin{array}{c}320.23(82.91) \\
\quad(\mathrm{N}=18)\end{array}$ & $\begin{array}{c}276.46(150.49) \\
\quad(\mathrm{N}=18)\end{array}$ & & $\begin{array}{c}393.99(145.63) \\
(\mathrm{N}=20)\end{array}$ & $\begin{array}{c}243.84(98.89) \\
(\mathrm{N}=17)\end{array}$ \\
\hline $\mathrm{p}$-value & & $<0.001^{\dagger}$ & $<0.001^{\dagger}$ & $<0.001^{*}$ & & $<0.001^{*}$ & $0.004^{\dagger}$ \\
\hline SHBG (nmol/L) & $30.04(13.89)$ & $\begin{array}{c}31.00(12.06) \\
(\mathrm{N}=24)\end{array}$ & $\begin{array}{c}28.21(12.55) \\
\quad(\mathrm{N}=19)\end{array}$ & $\begin{array}{c}29.64(14.03) \\
(\mathrm{N}=24)\end{array}$ & & $\begin{array}{c}27.35(10.55) \\
\quad(\mathrm{N}=23)\end{array}$ & $\begin{array}{c}28.79(15.60) \\
(\mathrm{N}=19)\end{array}$ \\
\hline p-value & & $0.533^{\dagger}$ & $0.990^{\dagger}$ & $0.744^{\dagger}$ & & $0.092^{\dagger}$ & $0.790^{*}$ \\
\hline \multicolumn{8}{|c|}{ Cholesterol (mg/dL) } \\
\hline Total & $195.40(42.23)$ & & $\begin{array}{c}176.79(25.41) \\
(\mathrm{N}=19)\end{array}$ & & & & $\begin{array}{c}179.47(32.54) \\
(\mathrm{N}=19)\end{array}$ \\
\hline p-value & & & $0.153^{*}$ & & & & $0.616^{*}$ \\
\hline HDL & $\begin{array}{c}44.26(10.59) \\
(\mathrm{N}=19)\end{array}$ & & $\begin{array}{c}43.89(8.08) \\
(\mathrm{N}=19)\end{array}$ & & & & $\begin{array}{c}44.16(7.65) \\
(\mathrm{N}=19)\end{array}$ \\
\hline p-value & & & $0.584^{\dagger}$ & & & & $0.530^{*}$ \\
\hline LDL & $\begin{array}{c}122.47(41.43) \\
(\mathrm{N}=19)\end{array}$ & & $\begin{array}{c}107.74(27.94) \\
(\mathrm{N}=19)\end{array}$ & & & & $\begin{array}{c}112.68(31.15) \\
(\mathrm{N}=19)\end{array}$ \\
\hline$p$-value & & & $0.930^{*}$ & & & & $0.644^{\dagger}$ \\
\hline Triglyceride & $176.68(161.47)$ & & $\begin{array}{c}145.31(106.94) \\
(\mathrm{N}=19)\end{array}$ & & & & $\begin{array}{c}143.20(118.74) \\
(\mathrm{N}=19)\end{array}$ \\
\hline p-value & & & $0.178^{*}$ & & & & $0.773^{*}$ \\
\hline HbA1C (\%) & $\begin{array}{c}6.40(0.76) \\
(\mathrm{N}=22)\end{array}$ & & & & & & $\begin{array}{c}9.68(13.53) \\
(\mathrm{N}=17)\end{array}$ \\
\hline$p$-value & & & & & & & $1.000^{*}$ \\
\hline HcT (\%) & $\begin{array}{l}41.46(3.45) \\
(\mathrm{N}=24)\end{array}$ & & $\begin{array}{l}45.25(3.38) \\
(\mathrm{N}=18)\end{array}$ & & $\begin{array}{l}45.13(4.33) \\
(\mathrm{N}=24)\end{array}$ & & $\begin{array}{c}46.18(4.72) \\
(\mathrm{N}=19)\end{array}$ \\
\hline$p$-value & & & $<0.001^{\dagger}$ & & $<0.001^{\dagger}$ & & $0.001^{\dagger}$ \\
\hline $\mathrm{Hb}(\mathrm{g} / \mathrm{dL})$ & $\begin{array}{l}13.96(1.27) \\
(\mathrm{N}=24)\end{array}$ & & $\begin{array}{c}15.20(1.14) \\
(\mathrm{N}=17)\end{array}$ & & $\begin{array}{c}14.99(1.65) \\
(\mathrm{N}=24)\end{array}$ & & $\begin{array}{c}15.45(1.50) \\
(\mathrm{N}=19)\end{array}$ \\
\hline$p$-value & & & $0.012^{\dagger}$ & & $<0.001^{\dagger}$ & & $0.001^{\dagger}$ \\
\hline $\begin{array}{l}\text { Prostate specific } \\
\text { antigen (PSA) } \\
(\mathrm{ng} / \mathrm{ml})\end{array}$ & $\begin{array}{c}0.92(0.72) \\
(\mathrm{N}=21)\end{array}$ & & $\begin{array}{c}1.98(1.87) \\
(\mathrm{N}=11)\end{array}$ & & $\begin{array}{c}1.44(1.33) \\
(\mathrm{N}=18)\end{array}$ & & $\begin{array}{c}1.78(1.31) \\
(\mathrm{N}=11)\end{array}$ \\
\hline $\mathrm{p}$-value & & & $0.002^{*}$ & & $0.008^{*}$ & & $0.004^{*}$ \\
\hline
\end{tabular}

*Wilcoxon signed rank test, compared with baseline. ${ }^{\dagger}$ Paired t-test, compared with baseline.

Table 5. Adverse events ( $N=25$ male patients).

\begin{tabular}{|c|c|c|c|c|c|}
\hline Adverse events ${ }^{*}$ & Number of patients & $\%$ & Relation to study drug & Intensity & Recovery \\
\hline Pain at injection site & 1 & 4.0 & Yes & Mild & Yes \\
\hline Frequent urination & 1 & 4.0 & No & Mild & Yes \\
\hline Stasis dermatitis & 1 & 4.0 & No & Mild & Yes \\
\hline Urinary tract infection & 1 & 4.0 & No & Mild & Yes \\
\hline
\end{tabular}

${ }^{*}$ All adverse events were in non-serious type.

placebo-controlled study of hypogonadal men with ED, the combination of sildenafil and 1\% testosterone-gel significantly improved erectile function and response to sildenafil. Additionally, the combination increased the IIEF scores at 4 weeks in patients who did not respond to sildenafil alone [15]. However, results in the testosteronegel group after 4 weeks were not significant due to patient dropout in this proof-of-concept study. Quality-of- 
life scores, however, were significantly improved at 12 weeks after combination therapy compared with placebo. In addition to erectile function, testosterone therapy improved orgasmic function [15]. In a randomized, placebocontrolled study, short-term transdermal testosterone administration improved the erectile response to sildenafil by increasing arterial inflow to the penis during sexual stimulation. Finally, testosterone was shown to improve arterial flow and subsequent response to tadalafil treatment, with a greater response after 10 weeks, compared to 4 weeks of pretreatment with testosterone [16-19]. Kim et al. suggest that combination therapy with testosterone supplementation in patients not responding to PDE-5 inhibitors was more beneficial to patients with severe testosterone depletion, possibly by improving underlying pathophysiology [9].

Other studies have confirmed the beneficial effects of combination therapy in patients with comorbid conditions. Administration of intramuscular testosterone and sildenafil was found to be efficacious in renal transplant patients and in patients on renal dialysis [20-22]. Oral testosterone has been reported to reverse ED associated with type 2 diabetes in patients failing on sildenafil therapy alone $[23,24]$. In this study, we demonstrate that combination treatment with long acting TU and vardenafil improves erectile function in patients with $\mathrm{LOH}$ and ED.

\section{Conclusion}

Testosterone combination therapy with PDE-5 inhibitors improves erectile function and the response to PDE-5 inhibitors in patients with ED and hypogonadism.

\section{REFERENCES}

[1] S. Zona, G. Guaraldi, K. Luzi, M. Beggi, D. Santi, C. Stentarelli, et al., "Erectile Dysfunction Is More Common in Young to Middle-Aged HIV-Infected Men than in HIV-Uninfected Men," Journal of Sexual Medicine, Vol. 9, No. 7, 2012, pp. 1923-1930. doi:10.1111/j.1743-6109.2012.02750.x

[2] M. Maggi, J. Buvat, G. Corona, A. Guay and L. O. Torres, "Hormonal Causes of Male Sexual Dysfunctions and Their Management (Hyperprolactinemia, Thyroid Disorders, GH Disorders, and DHEA)," Journal of Sexual Medicine, 2012. doi:10.1111/j.1743-6109.2012.02735.x

[3] L. Di Luigi, P. Sgro, V. Fierro, S. Bianchini, G. Battistini, V. Magini, et al., "Prevalence of Undiagnosed Testosterone Deficiency in Aging Athletes: Does Exercise Training Influence the Symptoms of Male Hypogonadism?" Journal of Sexual Medicine, Vol. 7, No. 7, 2010, pp. 2591-601.

[4] G. Corona, G. Rastrelli, L. Vignozzi, E. Mannucci and M. Maggi, "How to Recognize Late-Onset Hypogonadism in Men with Sexual Dysfunction," Asian Journal of Andro- logy, Vol. 14, No. 2, 2012, pp. 251-259. doi:10.1038/aja.2011.138

[5] G. Corona, G. Rastrelli, A. Morelli, L. Vignozzi, E. Mannucci and M. Maggi, "Hypogonadism and Metabolic Syndrome," Journal of Endocrinological Investigation, Vol. 34, No. 7, 2011, pp. 557-67.

[6] N. Bassil, "Late-Onset Hypogonadism," Medical Clinics of North America, Vol. 95, No. 3, 2011, pp. 507-523. doi:10.1016/j.mena.2011.03.001

[7] G. Antonini, A. Clemenzi, E. Bucci, E. De Marco, S. Morino, A. Di Pasquale, et al., "Hypogonadism in DM1 and Its Relationship to Erectile Dysfunction," Journal of Neurology, Vol. 258, No. 7, 2011, pp. 1247-1253. doi:10.1007/s00415-011-5914-3

[8] F. Romanelli, A. Sansone and A. Lenzi, "Erectile Dysfunction in Aging Male," Acta Bio Medica, Vol. 81, No. S1, 2010, pp. 89-94.

[9] J. W. Kim, M. M. Oh, M. G. Park, J. Y. Park, J. H. Bae, J. J. Kim, et al., "Combination Therapy of Testosterone Enanthate and Tadalafil on PDE5 Inhibitor Non-Reponders with Severe and Intermediate Testosterone Deficiency," International Journal of Impotence Research, 2012.

[10] P. Ellsworth and E. M. Kirshenbaum, "Current Concepts in the Evaluation and Management of Erectile Dysfunction," Urologic Nursing, Vol. 28, No. 5, 2008, pp. $357-$ 369.

[11] A. Morelli, G. Corona, S. Filippi, S. Ambrosini, G. Forti, L. Vignozzi, et al., "Which Patients with Sexual Dysfunction Are Suitable for Testosterone Replacement Therapy?" Journal of Endocrinological Investigation, Vol. 30, No. 10, 2007, pp. 880-888.

[12] J. Barkin, "Erectile Dysfunction and Hypogonadism (Low Testosterone)," The Canadian Journal of Urology, Vol. 18, 2011, pp. 2-7.

[13] I. A. Smith, N. McLeod and P. Rashid, "Erectile Dysfunction-When Tablets Don't Work," Australian Family Physician, Vol. 39, No. 5, 2010, pp. 301-305.

[14] A. Morales, J. Buvat, L. J. Gooren, A. T. Guay, J. M. Kaufman, H. M. Tan, et al., "Endocrine Aspects of Sexual Dysfunction in Men," Journal of Sexual Medicine, Vol. 1, No. 1, 2004, pp. 69-81. doi:10.1111/j.1743-6109.2004.10111.x

[15] R. Shabsigh, J. M. Kaufman, C. Steidle and H. PadmaNathan, "Randomized Study of Testosterone Gel as Adjunctive Therapy to Sildenafil in Hypogonadal Men with Erectile Dysfunction Who Do Not Respond to Sildenafil Alone," Journal of Urology, Vol. 172, No. 2, 2004, pp. 658-663. doi:10.1097/01.ju.0000132389.97804.d7

[16] J. Buvat, F. Montorsi, M. Maggi, H. Porst, A. Kaipia, M. H. Colson, et al., "Hypogonadal Men Nonresponders to the PDE5 Inhibitor Tadalafil Benefit from Normalization of Testosterone Levels with a 1\% Hydroalcoholic Testosterone Gel in the Treatment of Erectile Dysfunction (TADTEST Study)," Journal of Sexual Medicine, Vol. 8, No. 1, 2011, pp. 284-293. doi:10.1111/j.1743-6109.2010.01956.x

[17] A. A. Yassin and F. Saad, "Testosterone and Erectile Dysfunction," Journal of Andrology, Vol. 29, No. 6, 2008, pp. 
593-604. doi:10.2164/jandrol.107.004630

[18] F. Saad, L. J. Gooren, A. Haider and A. Yassin, "A DoseResponse Study of Testosterone on Sexual Dysfunction and Features of the Metabolic Syndrome Using Testosterone Gel and Parenteral Testosterone Undecanoate," Journal of Andrology, Vol. 29, No. 1, 2008, pp. 102-105. doi:10.2164/jandrol.107.002774

[19] A. A. Yassin and F. Saad, "Treatment of Sexual Dysfunction of Hypogonadal Patients with Long-Acting Testosterone Undecanoate (Nebido)," World Journal of Urology, Vol. 24, No. 6, 2006, pp. 639-644. doi:10.1007/s00345-006-0120-0

[20] R. Chatterjee, S. Wood, H. H. McGarrigle, W. R. Lees, D. J. Ralph and G. H. Neild, "A Novel Therapy with Testosterone and Sildenafil for Erectile Dysfunction in Patients on Renal Dialysis or after Renal Transplantation," Journal of Family Planning and Reproductive Health Care, Vol. 30, No. 2, 2004, pp. 88-90. doi: $10.1783 / 147118904322995438$

[21] G. Punzo, S. Maggi, R. Ponzio, M. Costarella and V. Gentile, "Use of Sildenafil in the Chronic Uremic Patient," Minerva Urologica e Nefrologica, Vol. 53, No. 1, 2001, pp. 39-43.

[22] B. F. Palmer, "Sexual Dysfunction in Uremia," Journal of the American Society of Nephrology, Vol. 10, No. 6, 1999, pp. 1381-1388.

[23] G. Jackson, "Sexual Dysfunction and Diabetes," International Journal of Clinical Practice, Vol. 58, No. 4, 2004, pp. 358-362. doi:10.1111/j.1368-5031.2004.00180.x

[24] S. Y. Kalinchenko, G. I. Kozlov, N. P. Gontcharov and G. V. Katsiya, "Oral Testosterone Undecanoate Reverses Erectile Dysfunction Associated with Diabetes Mellitus in Patients Failing on Sildenafil Citrate Therapy Alone," The Aging Male, Vol. 6, No. 2, 2003, pp. 94-99. 